\title{
CONFORMATIONS AND MUTAROTATIONS OF POLY(5-METHYL-L-PROLINE)
}

\author{
C. G. OVERBERGER and M. J. HAN
}

Department of Chemistry and the Macromolecular Research Center, The University of Michigan, Ann Arbor, Michigan 48104, USA

\begin{abstract}
Optically active poly(cis-5-methyl-L-proline) and poly(trans-5-methyl-L-proline) were synthesized from their respective $N$-carboxy-anhydrides (NCA). Analysis of the i.r., u.v., n.m.r., ORD, and CD spectra of the polymers showed that two different conformations of each polymer exist in the solid and in solution in appropriate solvents. Form I and form II of poly(trans-5-methylL-proline) were found to have the same conformations as the form I and form II of poly-L-proline, respectively. Form B of poly(cis-5-methyl-Lproline) seemed to have a somewhat different conformation from form II of poly-L-proline. The changes in viscosity during the mutarotations of the two polymers showed that the mutarotation entailed cis-trans isomerization of amide bonds in the polymers. By following the kinetics of the mutarotations it was found that the activation energies for poly(cis-5-methyl-L-proline) was $22 \mathrm{kcal}$ per residue mole, whereas $E_{\mathrm{a}}$ of poly(trans-5-methyl-L-proline) was $33 \mathrm{kcal}$ per residue mole. The excess $10 \mathrm{kcal}$ for the latter polymer was attributed partially to the steric barrier between the methyl group at the trans-5-

position and the carbonyl group in the polymer.
\end{abstract}

\section{INTRODUCTION}

The conformation of poly-L-proline (PP) has been studied in some detail by many investigators ${ }^{1}$. As determined by $\mathrm{x}$-ray diffraction, PP exists in two different conformations in the solid, namely form I, a right-handed helix with all cis-amide bonds, and form II, a left-handed helix with all transamide bonds ${ }^{2-4}$. It was concluded from optical rotatory dispersion (ORD) and circular dichroism (CD) measurements that these ordered structures are largely maintained in solution in appropriate solvents ${ }^{5-12}$. The two forms could be interconverted by changing the solvent compositions ${ }^{1}$. Since neither intra- or inter-molecular hydrogen bonding is possible in PP because of the absence of a hydrogen atom on nitrogen, the ordered structures were believed to be maintained by steric factors, van der Waals interactions between non-bonded atoms and dipolar interactions ${ }^{1}$.

It was felt that the introduction of a group in the 5-position of the prolyl ring might affect the steric and van der Waals interactions and thus influence the formation of the helical conformations and the mutarotations of the polymer. Thus, poly(5-methylproline) was synthesized. 5-Methylproline has two geometric isomers-cis and trans--and optical isomers $-D$ and $L-$ of each geometric isomer. We synthesized polymers of the four optical isomers. 

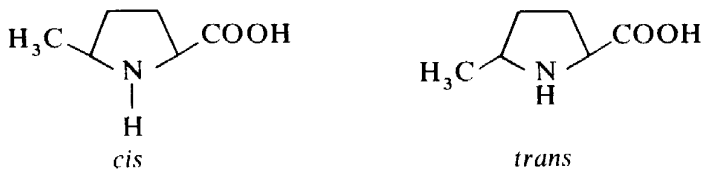

In this paper we report the conformations and mutarotations of the polymers, which were investigated by u.v., i.r., n.m.r., ORD and CD spectroscopy.

\section{POLYMERIZATION}

The polymers were formed from the $N$-carboxy-anhydride (NCA) of the amino acids. Proline ${ }^{13}$ and cis-5-methylproline (CMP) reacted with phosgene to form NCA in high yield at room temperature, whereas trans-5-methylproline (TMP) did not form the NCA under such conditions. However, its $\mathrm{N}$-carboxy-anhydride could be obtained in low yield at higher temperature $\left(50^{\circ} \mathrm{C}\right)$.

The polymerization of proline ${ }^{16} \mathrm{NCA}$ and cis-5-methylproline ${ }^{14} \mathrm{NCA}$ were successful in acetonitrile at room temperature initiated by sodium methoxide, yielding very high conversion of high molecular weight polymer. Contrary to these results, trans-5-methylproline NCA could not be polymerized under these conditions. Its polymerization could be effected in bulk with sodium methoxide at the temperature above the melting point of the NCA $\left(78^{\circ} \mathrm{C}\right)$. Under these polymerization conditions only oligomers were obtained. The poor polymerization tendency of trans-5-methylproline NCA was attributed to the fact that the methyl group in the trans-5-position hinders attack on the NCA, thus limiting propagation of the chain.

The polymerization of the NCAs of proline, cis-5-methylproline and trans-5-methylproline proceeded with the formation of polymers of definite conformation depending on the solvent and polymerization conditions (see Table 1). Several mechanisms have been suggested for the polymerization of amino acid NCAs initiated by amines and metal salts ${ }^{17}$. In each mechanism, the conformation of amide bonds in the polymers seemed to be determined in the propagation steps, because all the polymerizations in Table $I$ were precipitation polymerizations and because most of the solvents in Table 1

Table l. Formation of form I and II depending on the polymerization conditions of NCApolymerization

\begin{tabular}{lll}
\hline Polymers & Form I & Form II \\
\hline PP & $\begin{array}{l}\text { Pyridine }^{6} \\
\text { Dioxane }^{6} \\
\text { Acetonitrile }^{15}\end{array}$ & $\begin{array}{l}\text { Nitrobenzene } \\
\text { (Mixture of I and II) }\end{array}$ \\
\hline PTMP & $\begin{array}{l}\text { Bulk polymerization } \\
\text { above melting point }\left(788^{20} \mathrm{C}\right)\end{array}$ \\
\hline PCMP & $\begin{array}{l}\text { Form A } \\
\text { Acetonitrile }\end{array}$ & $\begin{array}{l}\text { Form B } \\
\text { Methylene chloride } \\
\text { Dioxane-water }\end{array}$ \\
\hline
\end{tabular}


do not induce the mutarotations of the polymers; cis-trans isomerization of the amide bond after their formation during the polymerization could be hardly expected.

\section{CONFORMATIONAL ANALYSIS BY SPECTRAL METHODS}

UV, ORD and CD spectra of form I and form II for the three polymers PP, PCMP and PTMP were recorded; the maximum wavelengths of the bands are summarized in Table 2. The absorption maxima in u.v. spectra of form I and form II for the three polymers show the wavelengths at 208-210 and 202-203 $\mathrm{m} \mu$, respectively. The peaks and troughs of the ORD-spectra for form I and form II for the three polymers occurred also in a very narrow wavelength range. In the $\mathrm{CD}$-spectra of form $\mathrm{I}$ of the three polymers, a negative band at 196-199 $\mathrm{m} \mu$ and a positive band at $215 \mathrm{~m} \mu$ were found.

Table 2. The maximum wavelengths of the spectral data for the three polymers

\begin{tabular}{|c|c|c|c|c|}
\hline Spectral methods & Forms & $\mathrm{PP}$ & РTMP & PCMP \\
\hline \multirow{2}{*}{ u.v. $\left(\lambda_{\max }\right)$} & I & 210 & 209 & $208(\mathrm{~A})$ \\
\hline & II & 202 & 203 & 203 (B) \\
\hline \multirow{2}{*}{$\operatorname{ORD}\left(\lambda_{\max }\right)$} & I & $\begin{array}{l}(-) 208 \\
(+) 223\end{array}$ & $\begin{array}{l}(-) 207 \\
(+) 224\end{array}$ & $\begin{array}{l}(-) \\
(+)\end{array} 222$ (A) \\
\hline & II & $(-) 216$ & $(-) 213$ & $\begin{array}{l}(+) 201 \\
(-) 219\end{array}$ (B) \\
\hline \multirow{2}{*}{$\operatorname{CD}\left(\lambda_{\max }\right)$} & I & $\begin{array}{l}(-) 199 \\
(+) 215 \\
(-) 232\end{array}$ & $\begin{array}{l}(-) 198.5 \\
(+) 215 \\
(-) 234\end{array}$ & $\begin{array}{l}(-) 196 \\
(+) 215(\mathrm{~A}) \\
(-) 234\end{array}$ \\
\hline & II & $\begin{array}{l}(-) 206 \\
(+) 226\end{array}$ & $\begin{array}{l}(-) 204 \\
(+) 224\end{array}$ & $\stackrel{(-)}{211}$ (B) \\
\hline
\end{tabular}

These bands were generally accepted as $\pi-\pi^{*}$ transitions ${ }^{18}$. A negative band around $232-234 \mathrm{~m} \mu$, assigned to $n-\pi^{*}$ transiton $^{18}$, was found in the CDspectra of three polymers. However, the CD-spectrum of PCMP, form B, does not show the weak band around $226 \mathrm{~m} \mu$ which seems to be the longer wavelength component of the split $\pi-\pi^{*}$ band ${ }^{11,18,19}$ and characteristic for the PP II-type helix.

The similarity of the above spectral data, together with the typical peaks of form I and form II in i.r. spectra, lead to the conclusion that PTMP form I and form II have the same helical conformation of PP form I and form II, namely a right-handed helix with all cis amide bonds and a lefthanded helix with all trans amide bonds. The absence of the weak positive band around $226 \mathrm{~m} \mu$ in the CD-spectrum of PCMP form B implies that its conformation is somewhat different from the helical structure of PP form II. In the study of the n.m.r. spectra, it was found that the $\delta$-protons remained nearly unchanged during the mutarotation of PP and PTMP. These differences are believed to be due to a small deviation of $\psi$ and/or $\omega$ angles in 
PCMP, form B, from those in PP, form II, conformation. However, since the deviation of $\omega$ angles associated with high energy changes because of the resonance energy of amide bond, it is more likely that the $\psi$ angle in PCMP, form $B$, is different from that in PP, form II.

\section{HYDROGEN BOND}

The forward mutarotation (I $\rightarrow$ II) of $\mathrm{PP}^{1}$ and PTMP occurred in organic acids and trifluoroethanol (TFE), whereas the reverse mutarotation resulted by dilution of acidic solutions of $\mathrm{PP}^{1}$ and TFE-solution of PTMP with aliphatic alcohols. The directions of the mutarotations of the two polymers (PP and PTMP) are the same in similar solvents (see Table 3). The reverse mutarotation $(\mathrm{B} \rightarrow \mathrm{A}$ ) of PCMP occurred in an aprotic solvent (chloroform),

Table 3. Solvents for the forward and reverse mutarotation of the polymers

\begin{tabular}{lll}
\hline Polymers & Forward mutarotation & Reverse mutarotation \\
\hline PP & $\begin{array}{l}\text { Organic acid } \\
\text { TFE }\end{array}$ & $\begin{array}{l}\text { Dilution of acidic solution with } \\
\text { alcohols (butanol, propanol) }\end{array}$ \\
PTMP & $\begin{array}{l}\text { Strong organic acids } \\
\text { MSA, TFA, DCA and TFE }\end{array}$ & $\begin{array}{l}\text { Dilution of TFE-solution with } \\
\text { alcohols (propanol, butanol) }\end{array}$ \\
PCMP & $\begin{array}{l}\text { (A } \rightarrow \text { B) } \\
\text { Organic acids MSA, TFA, DCA } \\
\text { Dilution of chloroform solution } \\
\text { with alcohols (methanol, ethanol, } \\
\text { n-propanol, n-butanol, } \\
\text { chloroethanol, TFE) }\end{array}$ \\
\hline
\end{tabular}

while the forward mutarotation $(\mathrm{A} \rightarrow \mathrm{B})$ of it resulted in protic solvents (acid and alcohol) which are capable of forming hydrogen bonds with the amide carbonyl of the polymer. The hydrogen bonding between solvent and polymer seems to be responsible for the forward mutarotation of PCMP on the basis of the following results:

(1) The rate of the forward mutarotation was increased with the increase of alcohol concentration, and with increasing the acidity of alcohols at the same concentration of alcohols.

(2) The carbonyl band is generally changed by hydrogen bonding in such a way that it is shifted to shorter wavelength, becoming broader with a corresponding decrease in band intensity. The i.r.-spectra were measured during reverse mutarotation in chloroform-chloroethanol $(100: 1 \mathrm{v} / \mathrm{v})$. The carbonyl band of form B occurred at $1640 \mathrm{~cm}^{-1}$ with weak intensity, whereas after the reverse mutarotation, the carbonyl band was found at the same position with strong intensity. The bottom of the band is wider for form $\mathrm{B}$ than for form $\mathrm{A}$.

(3) In mixtures of protic and aprotic solvents, an equilibrium between form $A$ and form $B$ was established. The equilibrium state was shifted to the side of form B by increasing the concentration of protic solvents. 
(4) The thermodynamics of the mutarotation of PCMP were investigated by the changes in optical rotation. The forward mutarotation was accompanied by a decrease in enthalpy and entropy, whereas the reverse mutarotation caused increases in enthalpy and entropy. These thermodynamic parameters can be interpreted by hydrogen bonding between carbonyl groups of polymer and the solvent (alcohol). The formation of hydrogen bonds during forward mutarotation decreases the enthalpy and the entropy of the system while the cleavage of it during the reverse mutarotation increases them.

(5) Studies of space-filling models showed that the carbonyl groups of form A were incorporated into the helical structure of polymer, while they were exposed on the surface of the helix of form B. The formation of hydrogen bonds of carbonyl groups with solvent is, therefore, more favorable for form $B$ than form A.

All of the above results lead to the conclusion that the conformational changes of PCMP in different solvents are due to the interaction between solvent and polymer: the protic solvents force the forward mutarotation of PCMP by formation of hydrogen bonds between solvents and carbonyl groups in the polymer, whereas the reverse mutarotation in aprotic solvent was forced by cleavage of hydrogen bonds, which caused the increase in entropy of the system.

\section{CHANGES IN SOLUTION PROPERTIES DURING MUTAROTATION}

Since the residue translation of PP, form I (all cis amide bonds), and PP, form II (all trans amide bonds), were found by $\mathrm{x}$-ray diffraction to be 1.85 and $3.12 \AA$, respectively ${ }^{1}$, the transition from a cis to a trans amide bond will cause an elongation of molecular shape and, hence, an increase in viscosity during the forward mutarotation. The viscosity change during the forward mutarotation of PP was measured in acetic acid, which was increased in reduced viscosity from 0.99 to 1.44 in 4 days $^{21}$.

Viscosity changes during forward mutarotation of PTMP (in TFE) and PCMP (in chloroethanol) were measured. The reduced viscosity of the former polymer was increased from 0.15 to 0.26 in 5 days and the latter polymer from 0.16 to 0.28 in 80 minutes. The viscosity changes of both the polymers show clearly that the forward mutarotation involved a cis-trans isomerization of amide bonds in the polymers.

The changes in the ORD-spectra during the forward and reverse mutarotation of PP and PTMP are quite similar. When form I of PP and PTMP are dissolved in solvents in which the forward mutarotation occurs, a positive band at $224 \mathrm{m \mu}$ and a negative band at $207 \mathrm{~m} \mu$ were observed immediately after dissolution, which is typical for form I. During the coarse of the mutarotation, the positive band disappeared, and a red-shift and a decrease in intensity of the negative band were observed. After several days the ORD-spectrum of form II of PP and PCMP resulted. The changes in ORD-spectra during the reverse mutarotation of PP and PTMP are similar and opposite to the change of ORD-spectra during the forward mutarotation. The parallel change in ORD-spectra during mutarotations of both polymers 
could be additional evidence that forms I and II of PP and PTMP have the same conformations. Changes in the ORD-spectra during the forward mutarotation of PCMP in TFE-water is shown in Figure 1. The peak at $221 \mathrm{~m} \mu$ and a trough at $207 \mathrm{~m} \mu$ disappeared during the forward mutarotation;

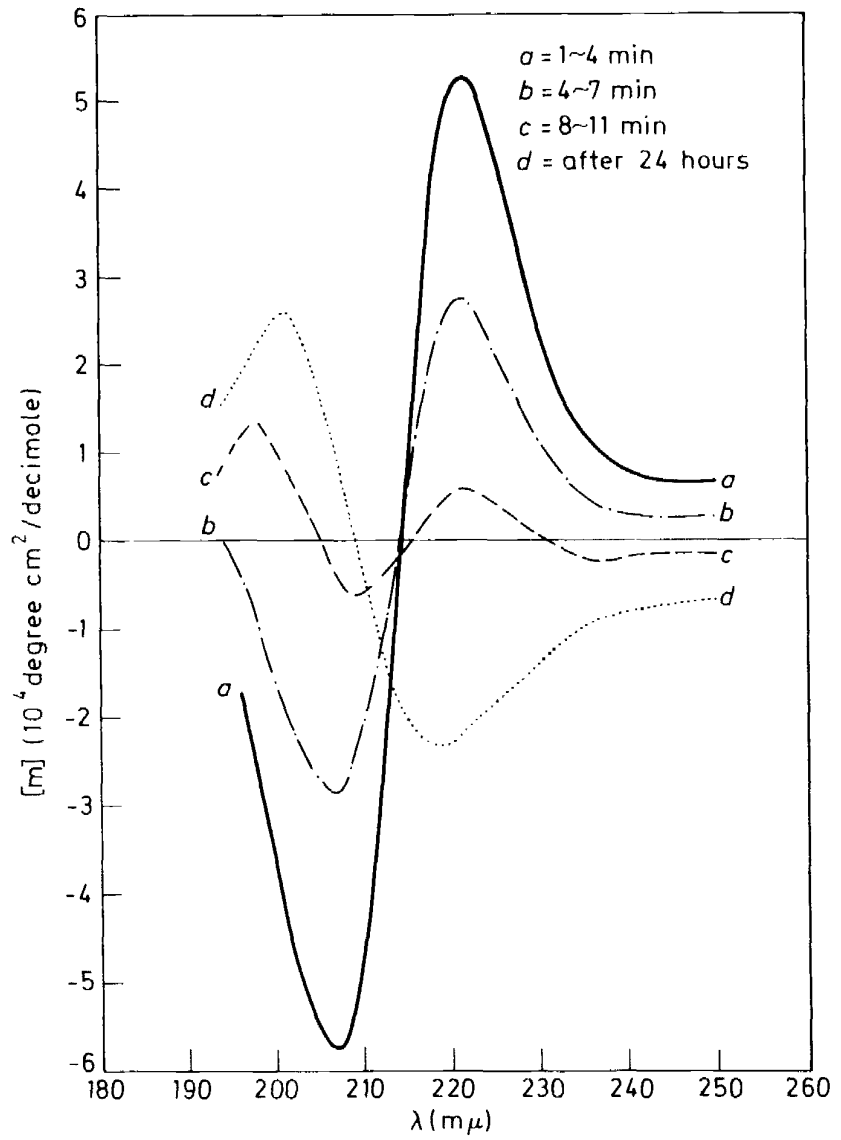

Figure 1. Change in ORD-spectra during the forward mutarotation of poly(cis-5-methyl-Lproline) in $\mathrm{TFE}-\mathrm{H}_{2} \mathrm{O}(9: 1)$ at $5 \mathrm{C}$.

the trough of form B at $219 \mathrm{~m} \mu$ appeared after disappearance of the trough at $207 \mathrm{~m} \mu$ of form A. The trend of the change in the ORD-spectra during forward mutarotation of PCMP is quite different from that of PP and PTMP. It is also interesting to note that the ORD-spectrum after 8-11 minutes during the forward mutarotation of PCMP shows two peaks at 208, $221 \mathrm{m \mu}$ and two troughs at $209,238 \mathrm{~m} \mu$ and has three inflection points at 205, 215, $231 \mathrm{~m} \mu$.

In the changes in $\mathrm{CD}$-spectra during forward mutarotation of $\mathrm{PP}^{1}$ and PTMP, the negative band of form II was formed by a red-shift and an increase in intensity of the negative band at $198 \mathrm{~m} \mu$ of form I. The positive 
band at approximately $225 \mathrm{~m} \mu$ in the CD-spectra of form II of PP and PTMP was formed by a decrease in intensity and a red-shift of the positive band at $215 \mathrm{~m} \mu$ of form I of both PP and PTMP.

The change in the CD-spectra during the forward mutarotation of PCMP in TFE-water $(9: 1 \mathrm{v} / \mathrm{v})$ at $5{ }^{\circ} \mathrm{C}$ is shown in Figure 2. Contrary to

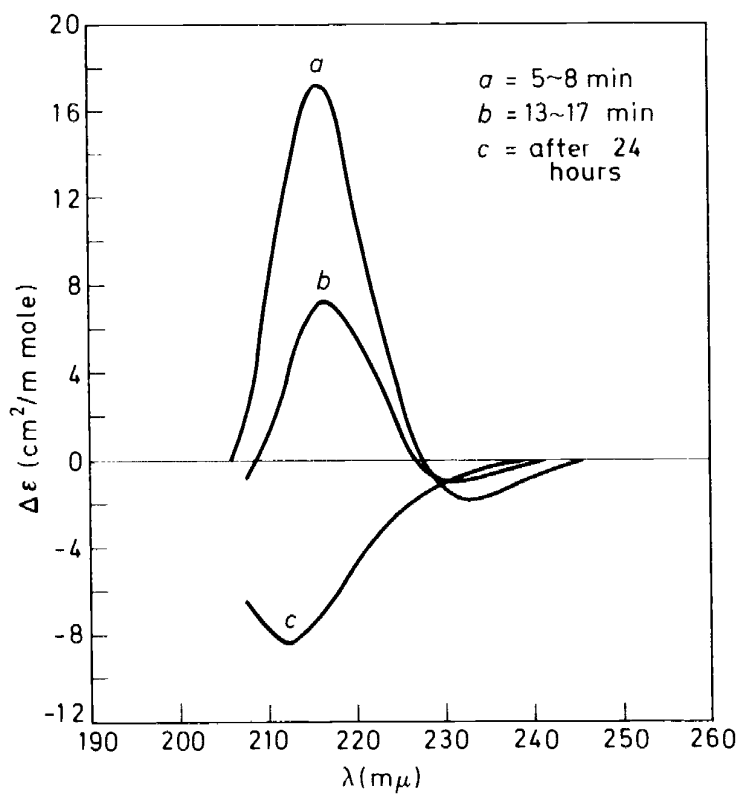

Figure 2. Change in CD-spectra during the forward mutarotation of poly(cis-5-methyl-Lproline) in TFE- $\mathrm{H}_{2} \mathrm{O}(9: 1)$ at $5^{\circ} \mathrm{C}$.

the typical changes of form I to form II of PP and PTMP, the negative bands at 196 and $234 \mathrm{~m} \mu$ disappeared at an early stage of the mutarotation. After 24 hours the mutarotation was complete and the CD-spectrum of form B showed a strong negative band at $211 \mathrm{~m} \mu$. The positive band at $215 \mathrm{~m} \mu$ of PCMP form I disappeared during the forward mutarotation and hence the characteristic band of form II of PP and PTMP at around $225 \mathrm{~m} \mu$ was not observed in the CD-spectrum of PCMP, form B.

\section{KINETICS OF MUTAROTATION}

The kinetics of the mutarotation of PP have been investigated by several researchers using optical rotation and n.m.r. spectra, both of which changed during the mutarotation of PP. The forward mutarotation was found to be of zero-order with respect to polymer concentration by n.m.r. spectroscopy ${ }^{22}$, and first-order with respect to the polymer concentration for the forward and reverse mutarotation of PP by optical rotation techniques ${ }^{23+24}$. This discrepancy has not been resolved. However, the activation energy for the mutarotation was found to be $20-24 \mathrm{kcal}$ per residue mole ${ }^{22-24}$, 
which is similar to the resonance energy of the amide bond and hence contributed to the conclusion that mutarotation of PP is a cis-trans isomerization of amide bonds in the polymer.

The kinetics for the mutarotation of PTMP were measured by the change of differential dichroic absorption at $217 \mathrm{~m} \mu$. The rates of mutarotation of PTMP were much slower than that of PP under the same conditions. The activation energies for the forward and reverse mutarotation were found to be 32.5 and $33.5 \mathrm{kcal}$ per residue mole, respectively.

The kinetics of the forward and reverse mutarotation of PCMP were measured by the change in optical rotation at $243 \mathrm{m \mu}$ in chloroformmethanol $(10: 1, \mathrm{v} / \mathrm{v})$ and at $265 \mathrm{~m} \mu$ in chloroform-chloroethanol $(200: 1$, $\mathrm{v} / \mathrm{v}$ ), respectively. The kinetic measurement for the forward mutarotation with three different concentrations revealed that the reaction was of firstorder.

The changes in optical rotation at $265 \mathrm{~m} \mu$ during the reverse mutarotation at four different temperatures is shown in Figure 3. The activation energies for the mutarotations were evaluated by the modified Arrhenius equation $(1)^{26}$.

$$
\ln \left(\frac{t_{\mathrm{a}}}{t_{\mathrm{b}}}\right)=\frac{E_{\mathrm{a}}}{R}\left(\frac{1}{T_{\mathrm{a}}}-\frac{1}{T_{\mathrm{b}}}\right)
$$

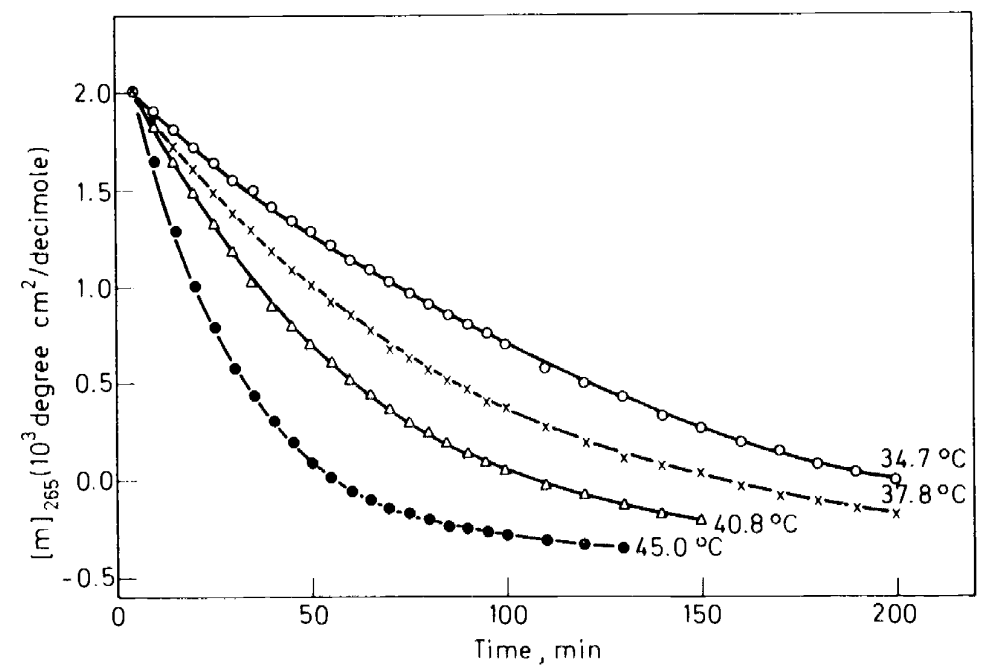

Figure 3. The changes in optical rotation at $265 \mathrm{~m} \mu$ during the reverse mutarotation of PCMP at four different temperatures in choroform-chloroethanol $(200: 1, v / v)$.

$t_{\mathrm{a}}$ and $t_{\mathrm{b}}$ are the times required to mutarotate to a given optical rotation at two different temperatures, $T_{\mathrm{a}}$ and $T_{\mathrm{b}}$, respectively. Figure 4 shows the plot of equation (1) and the activation energy, evaluated from the slope, was fould to be $23.9 \mathrm{kcal}$ per residue mole. The activation energy for the forward mutarotation was measured by the same method.

The values of activation energies for the forward and reverse mutarotations of the three polymers are shown in Table 4 . The value of $E_{\mathrm{a}}$ for the mutarota- 


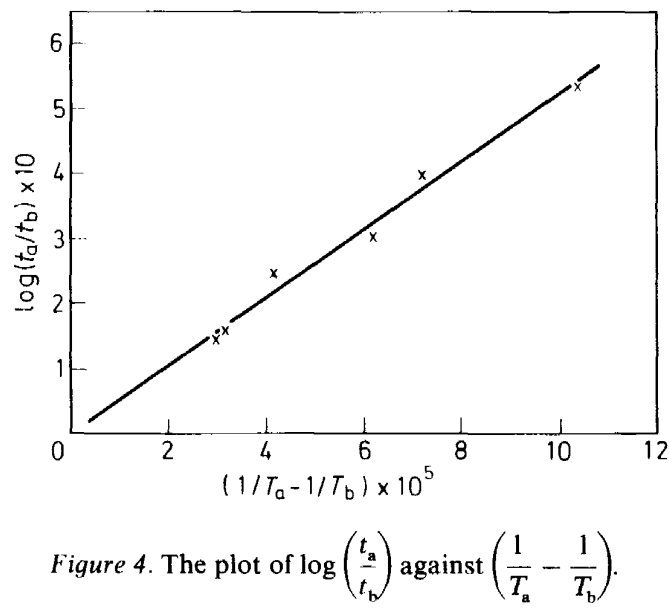

tion of PCMP is similar to that of PP, which implies that the introduced methyl group at cis-5-position has no steric influence on the cis-trans isomerization of amide bonds in PCMP. In contrast to PCMP, the value of $E_{\mathrm{a}}$ for the mutarotation of PTMP is about $10 \mathrm{kcal}$ per residue mole higher

Table 4. Activation energies for the mutarotations of the three polymers

\begin{tabular}{lll} 
Polymers & $\begin{array}{l}\text { Forward mutarotation } \\
(\mathrm{kcal} / \text { residue mole })\end{array}$ & $\begin{array}{l}\text { Reverse mutarotation } \\
(\mathrm{kcal} / \text { residue mole })\end{array}$ \\
\hline PP & $22.9^{23}$ & \\
& $\left(\mathrm{CH}_{3} \mathrm{COOH}\right)$ & $20.6(\Delta H \dagger)^{24}$ \\
& $20.6\left(\Delta \mathrm{H}^{24}\right)^{24}$ & \\
$\left(\mathrm{CH}_{3} \mathrm{COOH}\right)$ & \\
& $23.0^{22}$ & \\
& $\left(\mathrm{D}_{2} \mathrm{O}\right)$ & 33.5 \\
& 32.5 & $(\mathrm{TFE} \mathrm{BuOH})$ \\
PTMP & $(\mathrm{TFE})$ & 23.9 \\
& 21.4 & $\left(\mathrm{CHCl}_{3}-\mathrm{ClCH}_{2} \mathrm{CH}_{2} \mathrm{OH}\right)$ \\
\hline PCMP & $\left(\mathrm{CHCl}_{3} \mathrm{MeOH}\right)$ & \\
\hline
\end{tabular}

than the resonance energy of the amide bond ${ }^{25}$. Figure 5 shows a Newman projection of one amide bond in PTMP in the direction from amino to terminal carbonyl. Studies of space filling models showed clearly that the methyl group in the trans-5-position was directed on the paper plane leading to steric hindrance between carbonyl and methyl groups during cis-trans isomerization of the amide bond. The cis-5-methyl group is directed behind the paper plane so that no steric hindrance during $180^{\circ}$ rotation around the carbonyl group was observed.

The activation energies for the reverse mutarotation of PCMP and PTMP are found to be 1-2 kcal per residue mole higher than those for the forward mutarotation. This difference can be ascribed to either the different solvent 
systems for each mutarotation or different enthalpies of the two forms of each of the polymers. The measurement of enthalpy changes for the mutarotation of PCMP showed that the form A enthalpy is several hundred calories more than form B in several solvent compositions.

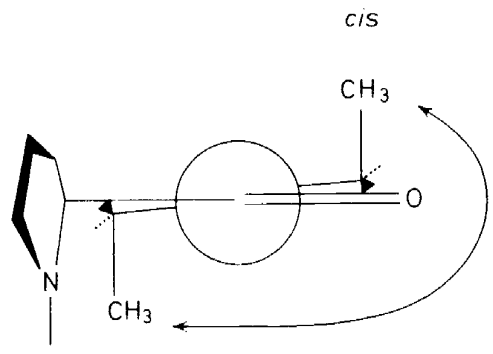

trans

Figure 5. Newman projection of the amide bond in PTMP and PCMP.

Figure 6 shows the plot of $\log \left([m]_{t}-[m]_{\infty}\right)$ against time, calculated from Figure 3, for the reverse mutarotation of PCMP at four different temperatures. Nearly linear relationships are obtained for the whole course of the reverse mutarotation. After evaluation of the apparent rate constants $\left(k^{\prime}\right)$ from the slopes, an activation energy $23.6 \mathrm{kcal}$ per residue mole was obtained from the simple Arrhenius plot of $\log k^{\prime}$ versus the reciprocal of absolute



Figure 6. The plot of $\log \left([\mathrm{m}]_{t}-[\mathrm{m}]_{x}\right.$ ) against time for the reverse mutarotation of PCMP at four different temperatures in chloroform-chloroethanol $(200: 1, \mathrm{v} / \mathrm{v})$. 
temperature. This value is in good agreement with the value of $E_{\mathrm{a}}$ evaluated by equation (1). The close agreement of activation energies, evaluated by both methods, leads to the conclusion that the molar optical rotation is proportional to the concentration of trans amide bonds and the reverse mutarotation obeys first-order kinetics, since the $E_{\mathrm{a}}$ obtained by Arrhenius plot was evaluated by the rate constants for first-order kinetics.

\section{SUMMARY AND CONCLUSIONS}

The result of the investigations of PCMP and PTMP are summerized by considering the influence of the introduced methyl group on the cis- and the trans-5-position of prolyl ring on the chemistry of PCMP and PTMP with PP as follows.

The methyl group at the trans-5-position of the prolyl ring hinders the polymerization to such an extent that only oligomers were obtained. However, the oligomers obtained have the same conformations as PP, form I and form II. cis-trans Isomerization of amide bonds in PTMP was hindered by the trans-5-methyl group and the steric barrier between methyl and carbonyl groups was found to be about $10 \mathrm{kcal}$ per residue mole.

The methyl group at the cis-5-position in prolyl ring does not hinder the polymerization which results in polymer of high molecular weight. The $\mathrm{CD}$ and n.m.r. spectra showed that the conformation of form B is somewhat different from that of PP, form II, presumably due to some deviation of the $\psi$ angle due to the steric hindrance of the methyl group in PCMP form B. The cis-trans isomerization of the amide bonds in PCMP was not influenced by the cis-5-methyl group.

The increase in viscosity during the forward mutarotation of the three polymers indicates that the forward mutarotation involves the cis-trans isomerization of amide bonds in the polymers. The difference in changes of the ORD and CD spectra for the forward mutarotation of PCMP from those of PP and PTMP might be attributed to the difference in the conformations of form B of PCMP and form II of PP and PTMP.

\section{ACKNOWLEDGEMENTS}

We thank the National Science Foundation for financial support under Grant No. GP-33833X, and the Macromolecular Research Center at The University of Michigan for Fellowship support. We also thank Dr. V. Bulacovschi for the preparation of DSH.

\section{REFERENCES}

${ }^{1}$ L. Mandelkern in Poly- $\alpha$-Amino Acids, ed. G. D. Fasman, Marcel Dekker, New York, 1967, p. 675 .

2 W. Traub and W. W. Shnnieli in Aspects of Protein Structure, ed. G. N. Ramachandran, Academic Press, New York, 1963, p. 81.

3 P. M. Cowan and S. McGavin, Nature, 176, 501 (1959).

4 V. Saisekharan, Acta Cryst. 12, 897 (1959).

5 E. R. Blount, J. P. Varner and J. Gross, J. Amer. Chem. Soc. 85, 644 (1963).

${ }^{6}$ F. A. Bovey and F. P. Hood, J. Amer. Chem. Soc. 88, 2326 (1966). 


\section{G. OVERBERGER AND M. J. HAN}

7 G. D. Fasman and E. R. Blount, Biopolymers, 1, 3 (1963).

8 J. P. Carver, E. Schechter and E. R. Blout, J. Amer. Chem. Soc. 88, 2550 (1966).

9 F. A. Bovey and F. P. Hood, Biopolymers, 5, 325 (1967).

${ }^{10}$ H. Okayabashi, T. Isemura and S. Sakakibara, Biopolymers, 6323 (1968).

11 M. L. Tiffany and S. Krimm, Biopolymers, 6, 1767 (1968).

12 W. L. Mattice and L. Mandelkern, Biochemistry, 9, 1049 (1970).

13 A. A. Randall, J. Chem. Soc. 374 (1962).

14 C. G. Overberger and K.-H. David, Macromolecules, 5, 373 (1972).

15 G. D. Fasman and E. R. Blout, Biopolymers, 1, 3 (1963).

16 A. Berger, J. Kurtz and E. Katchalski, Nature, 178, 1066 (1956).

17 E. Katchalski and M. Sela in Advances in Protein Chemistry, Vol. XIII, Academic Press, New York, 1953, p. 243.

18 E. S. Pysh, J. Mol. Biol. 23, 587 (1967).

19 K. Rosenheck, H. Miller and Zakaria, Biopolymers, 7, 614 (1969).

${ }^{20}$ E. C. Pimentel and A. L. McClellan in The Hydrogen Bond, W. H. Freeman, San Francisco, 1960.

${ }^{21}$ E. R. Blout and G. D. Fasman in Recent Advances Gelatin Glue Research, Proc. Conf. University Cambridge, 1957, 1, 122.

22 D. A. Torchia and F. A. Bovey, Macromolecules, 4, 246 (1971).

23 A. R. Downie and A. A. Randll, Trans. Farad. Soc. 55, 2132 (1959).

24 I. Z. Steinberg, W. F. Harrington, A. Berger, M. Sela, and E. Katchalski, J. Amer. Chem. Soc. 82, 5263 (1960).

25 L. Pauling and J. Sherman, J. Chem. Phys. 1, 606 (1933).

${ }^{26}$ C. G. Overberger, G. Montaudo, R. C. Glowaky, and M. J. Han, Proceedings of IUPAC, Helsinki, 1 (1972). 